Tannen, D. (1989) Talking Voices : Repetition, Dialogue, and Imagery in Conversational Discourse, Cambridge England ; New York: Cambridge University Press.

ten Have, P. (1999) Doing conversation analysis : a practical guide, London ; Thousand Oaks, Calif:: Sage Publications.

Tuler, S. (2000) Forms of talk in public dialogue: Distinguishing between adversarial and collaborative discourse. Journal of Risk Research 3, 1-17.

Tulloch, J. and D. Lupton (2003) Risk and Everyday Life, London: Sage.

Waterton, C. and B. Wynne (1999) Can focus groups access community views?, in R. S. Barbour and J. Kitzinger (ed.).Developing Focus Group Research. 127143.London: Sage.

Wray, A. (2002) Formulaic Language and the Lexicon, Cambridge: Cambridge University Press.

Wynne, B. (1995) Public Understanding of Science, in S. Jasanoff, G. E. Markle, J. C. Peterson and T. Pinch (ed.).Handbook of Science and Technology Studies. 361388. Thousand Oaks: Sage.

Wynne, B. (1996) Misunderstood misunderstandings: social identities and the public uptake of science, in A. Irwin and B. Wynne (ed.).Misunderstanding Science? The Public Reconstruction of Science and Technology. 19-46.Cambridge: Cambridge University Press.

Wynne, B. (2001) Creating public alienation: Expert cultures of risk and ethics on GMOs. Science as Culture 10, 445-481.

Yearley, S. (1987) Demotic logic: causal discourse and the structure of explanations. Text 2, 181-203. 
Kinneavy, J. L. (1971) A Theory of Discourse, Englewood Cliffs, NJ: Prentice-Hall.

Lanham, R. (1968) A Handlist of Rhetorical Terms, Berkeley, CA: University of California Press.

Lupton, D. (1999) Risk, London: Routledge.

Lupton, D. and J. Tulloch (2002) "Risk is part of your life': risk epistemologies among a group of Australians. Sociology 36, 317-34.

Macnaghten, P. and G. Myers (2003) Focus groups, in J. G. Giampietro Gobo, Clive Seale, David Silverman (ed.).Qualitative Research Practice. 65-79.London: Sage.

Macnaghten, P. and J. Urry (1998) Contested Natures, London: Sage.

McCarthy, M. (1998) Spoken Language and Applied Linguistics, Cambridge: Cambridge University Press.

McCarthy, M. and R. Carter (2004) 'There's millions of them': Hyperbole in everyday conversation. Journal of Pragmatics 36(2), 149-184.

Michael, M. (1996) Ignoring science: discourses of ignorance in the public understanding of science, in A. Irwin and B. Wynne (ed.).Misunderstanding Science? The Public Reconstruction of Science and Technology. 107125.Cambridge: Cambridge University Press.

Moon, R. (1998) Fixed Expressions and Idioms in English: A Corpus-Based Approach, Oxford: Oxford University Press.

Myers, G. (1998) Displaying opinions: Topics and disagreement in focus groups. Language in Society 27(1), 85-111.

Myers, G. (2004) Matters of Opinion: Talking about Public Issues, Cambridge: Cambridge University Press.

Myers, G. and P. Macnaghten (1998) Rhetorics of environmental sustainability: commonplaces and places. Environment and Planning A 30(2), 333-353.

Parr, J. (2005) Local water diversely known: Walkerton Ontario, 2000 and after. Environment and Planning D: Society and Space 23.

Plough, A. and S. Krimsky (1987) The emergence of risk communication studies: Social and political context. Science, Technology \& Human Values 12, 4-10.

Pomerantz, A. (1986) Extreme case formulations: a way of legitimising claims. Human Studies 9, 219-230.

Puchta, C. and J. Potter (2003) Focus Group Practice, London: Sage.

Richardson, K. (2003) Health risks on the internet: establishing credibility on-line. Health Risk and Society 5(2), 171-184.

Richardson, K. (2005) Internet Discourse and Health Debates, London: Palgrave.

Schegloff, E. and H. Sacks (1973) Opening up closings. Semiotica 8, 289-327.

Schiffrin, D. (1987) Discourse markers, Cambridge: Cambridge University Press.

Shotter, J. (1993) Conversational Realities: Constructing Life Through Language, Thousand Oaks, CA: Sage.

Silverman, D. (1998) Harvey Sacks : social science and conversation analysis, Cambridge: Polity.

Slovic, P. (1987) Perception of Risk. Science 236, 280-285.

Slovic, P. (2001) The Perception of Risk, London: Earthscan. 


\section{References}

Aristotle (1954) Rhetoric and Poetics, New York: Modern Library.

Beck, U. (1992) Risk Society: Towards a New Modernity, London: Sage.

Billig, M. (1987) Arguing and Thinking : A Rhetorical Approach to Social Psychology, Cambridge ; Paris: Cambridge University Press : Editions de la Maison de l'Homme.

Bloor, M., J. Frankland, et al. (2001) Focus Groups in Social Research, London: Sage.

Boltanski, L. (1999) Distant Suffering, Cambridge: Cambridge University Press.

Burke, K. (1984) Attitudes Towards History, Berkeley, CA: University of California Press.

Burningham, K. and D. Thrush (2004) Pollution concerns in context: a comparison of local perceptions of the risks associated with living close to a road and a chemical fctory. Journal of Risk Research 7(2), 213-232.

Carter, R. (2004) Language and Creativity: The Art of Common Talk, London: Routledge.

Cook, G. (2004) Genetically Modified Language, London: Routledge.

Douglas, M. and A. Wildavsky (1982) Risk and Culture: An Essay on the Selection of Technological and Environmental Dangers, Berkeley, CA: University of California Press.

Frewer, L. J., S. Hunt, et al. (2003) The views of scientific experts on how the public conceptualize uncertainty. Journal of Risk Research 6(1), 75-85.

Gigerenzer, G. (2002) Reckoning with Risk: Learning to Live with Uncertainty, London: Penguin.

Ginzberg, C. (1994) Killing a Chinese Mandarin: the moral implications of distance. New Left Review(298), 107-119.

Goffman, E. (1955) On face-work: An analysis of ritual elements in social interaction. Psychiatry: Journal for the Study of Interpersonal Processes 3, 213-231.

Gregory, R. S. and T. A. Satterfield (2002) Beyond perception: The experience of risk and stigma in community contexts. Risk Analysis 22(2), 347-358.

Hamilton, J. D. (2003) Exploring technical and cultural appeals in strategic risk communication: The Fernald Radium case. Risk Analysis 23(2), 292-302.

Hansson, S. O. (2004) Fallacies of risk. Journal of Risk Research 7(3), 353-360.

Hausendorf, H. and A. Bora, Eds. (2006) Analysing Citizenship Talk: Analysing Citizenship Talk: Social Positioning in Political and Legal Decision-Making Processes. Amsterdam: John Benjamins Publishing Company.

Heritage, J. (1984) Garfinkel and ethnomethodology, Cambridge; New York: Polity Press.

Hinchliffe, S. (1996) Helping the earth begins in the home: the social construction of environmental responsibilities. Global Environmental Change 6, 53-62.

Horlick-Jones, T. (2005) Informal logics of risk: contingency and modes of practical reasoning. Journal of Risk Research 8, 253-272.

Hutchby, I. and R. Wooffitt (1998) Conversation analysis : principles, practices and applications, Malden, Mass.: Polity Press.

Irwin, A. and B. Wynne, Eds. (1996) Misunderstanding Science. Cambridge: Cambridge University Press. 


\section{Appendix 2 - Transcription conventions}

full stop (.) for a short pause

underlining for stressed syllables

angle brackets $><$ for passages spoken faster than the surrounding talk

forward slash marks / for the onset of talk overlapping with the next line down

brackets $[\mathrm{mm}]$ for backchannel utterances from the moderator

Speaker names are pseudonyms; M or F denote speakers who could not be identified. 


\section{Acknowledgements}

A version of this paper was presented at the Centre for Language and Communication, Cardiff University. I would like to thank all the researchers who allowed me access to their focus group data. Tom Horlick-Jones and Graham Smart made useful comments and suggested readings.

\section{Appendix 1 - Sources of data}

Examples are drawn from six research projects at the Centre for the Study of Environmental Change and the Institute for Environmental Philosophy and Public Policy, Lancaster University: 'Public Perceptions and Sustainability in Lancashire', funded by Lancashire County Council; 'Public Rhetorics of Sustainability', funded by UK Economic and Social Research Council (ESRC), grant number R000221347; 'Uncertain World: Genetically Modified Organisms, Food and Public Attitudes in Britain' (in association with Unilever); 'Global Citizenship and the Environment', also funded by the ESRC, grant number R000236768; 'The Front End of the Front End: Mapping Public Concerns about Radioactive Waste Management Issues', funded by Nirex; 'Animal Futures: Public Attitudes and Sensibilities towards Animals and Biotechnology in Contemporary Britain', funded by the (UK) Agriculture and Environmental Biotechnology Commission. Thanks to Jane Hunt, Phil Macnaghten, Peter Simmons, Bronislaw Szerszynski, Mark Toogood, John Urry, and Brian Wynne. Further details on the projects and publications from them will be found at http://domino.lancs.ac.uk/ieppp/home.nsf 
reflexively about these commonplaces, but they are unlikely to do so to an interlocutor who presents himself or herself as above everyday devices of interaction.

Some approaches to public consultations on risk have suggested that institutions pay more attention to the ways people talk - narratives, metaphors, frames, identification or disidentification with others, laughter (Waterton and Wynne, 1999; Tuler, 2000; Hamilton, 2003; Horlick-Jones, 2005; Hausendorf and Bora, 2006). I am suggesting that we will find the regular patterns of formulaic response to risk, not just in mental structures, but in the demands of talk, in the turn by turn construction of an interaction. The lesson of this study, and of others along these lines, is that statements about risk issues are made in interactions with other people. These participants in focus groups, strangers to each other, together just for a couple hours, display extraordinary care in dealing with possible threats to the face of others present. Risk communicators must take similar care, about who is talking, to whom, and in what immediate context, if they want to participate in a dialogue. 
I am not, of course, suggesting that risk researchers, risk communicators and planners of public consultations adopt the use of commonplaces in their texts, just because lay people use them effectively. Commonplaces may be used to support a statement that is just wrong (see the first example in this paper). And they may not even be effective for the institutions; as I suggested in the introduction, they work for participants in focus groups - that is, they routinely go unchallenged - because they resolve a conversational dilemma. Used out of the conversational context, in a campaign by a government agency, non-governmental organization, or corporation, the same commonplaces would sound wrong, like a politician quoting a pop song lyric or an advertisement slightly misusing current slang.

Nor am I suggesting that studies of public perceptions of risk give commonplaces special weight, as if all attitudes could be reduces to a small set of general statements. Commonplaces are crafted for the moment, for this particular slot, and their frequency of occurrence and robustness under conversational challenge does not mean they are more deeply or generally felt than other statements. Moderators of focus groups and others involved in public consultations may want to challenge commonplaces, reopen topics closed by them, disrupt the balance and stasis of neatly opposed pairs. Or they may want to use them as prompts, taking their familiarity, the recognisability as the sort of thing people usually say, as a starting point for further discussion. The moderator need not respond to a commonplace with another commonplace, or follow any of these other patterns, because the moderator has a special role (Myers, 2004); but he or she cannot opt out of the face issues involved in any talk about risk issues. People can talk 
The various categories of commonplaces I have discussed make up a kind of folk theory of risk.

- possibility focuses on the issue of uncertainty

- $\quad$ scale focuses on the issue of calculation

- proximity focuses on issues of agency

- $\underline{\text { time }}$ focuses on issues of cause/effect and morality

- $\quad$ self and other focuses on issues of responsibility

Of course these themes are already familiar to risk researchers, and their frequent occurrences in lay talk may show, in part, the degree to which technical risk discourses have entered everyday discourses (see for instance Example 3). People come to surveys, interviews, and focus groups with formulaic ways of talking about risk, based on the ways they interact with people in talking about other problematic issues.

The various commonplaces are not necessarily consistent with each other; indeed, each commonplace has at least one that contradicts it. For instance, the assertion that anything can be a risk can be paired with the assertion that one can't worry about every possible risk; the comparison of a large danger with a smaller danger can be paired with another comparison in which the immediate takes precedence over the distant. The rhetorical usefulness of commonplaces is that they can express the contradictions people feel in their daily experience of risk issues, and contain them in a way that allows the talk to go on. That is why the response to a commonplace is not usually the kind of critical analysis that an academic risk specialist might wish; it is another commonplace, a turn that says 'on the other hand' while remaining in the same realm of shared beliefs and rhetorical practices. 


\section{deaths there haven't they [yes]}

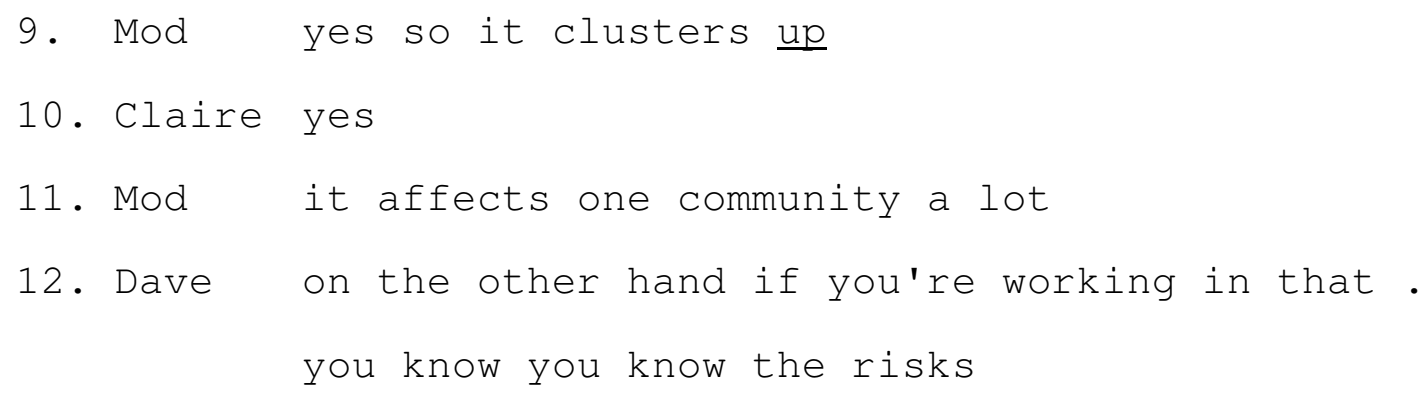

The moderator signals recognition in turn 9 ('yes so') and then reformulates Claire's turn with the word 'cluster', linking this argument to the running arguments on excess cases of childhood leukaemia. Rather than respond to this, Dave introduces another issue as relevant here: if people work there, they know (and have implicitly agreed to) the risks. The 'on the other hand' marks this as part of a contrary pair of commonplaces. None of the participants challenges the quantitative basis of the comparisons made by Dave, Di, or Claire (or those of the nuclear industry); they conduct their discussion in terms of commonplaces that address what they see as the moral dilemmas of self and others.

\section{Discussion}

As I noted at the outset, I would expect many qualitative researchers on risk to find commonplaces in their data, and to see the pattern of dilemma followed by commonplace followed by commonplace. I argue that this frequent use of commonplaces 1) displays a range of public concerns, 2) shows that these concerns are treated in terms of dilemmas, necessary contradictions, 3) shows these dilemmas are treated as potentially sensitive in dealing with other people, and 4) shows the care people take in dealing with risk issues in interaction. 
technological developments continue uncontrollably, and that what 'they' can't do by genetic means they will do by chemical means.

These issues of responsibility of one person to another are the central problem for industry claims that a given risk is small. But even a small risk can be unacceptable if one group benefits while the risks are run by someone else (cf. Hamilton, 2003). In Example 7, the Moderator presents in summary the case made in nuclear industry statistics, and the first two responses accept the comparison to ordinary risks (electricity and driving), risks often mentioned in these arguments (and discussed earlier under Scale). But then Claire offers a more complex argument, in which the small increase in cancers would be borne entirely by one geographical area:

\section{Example 7 - Front End: Burnham}

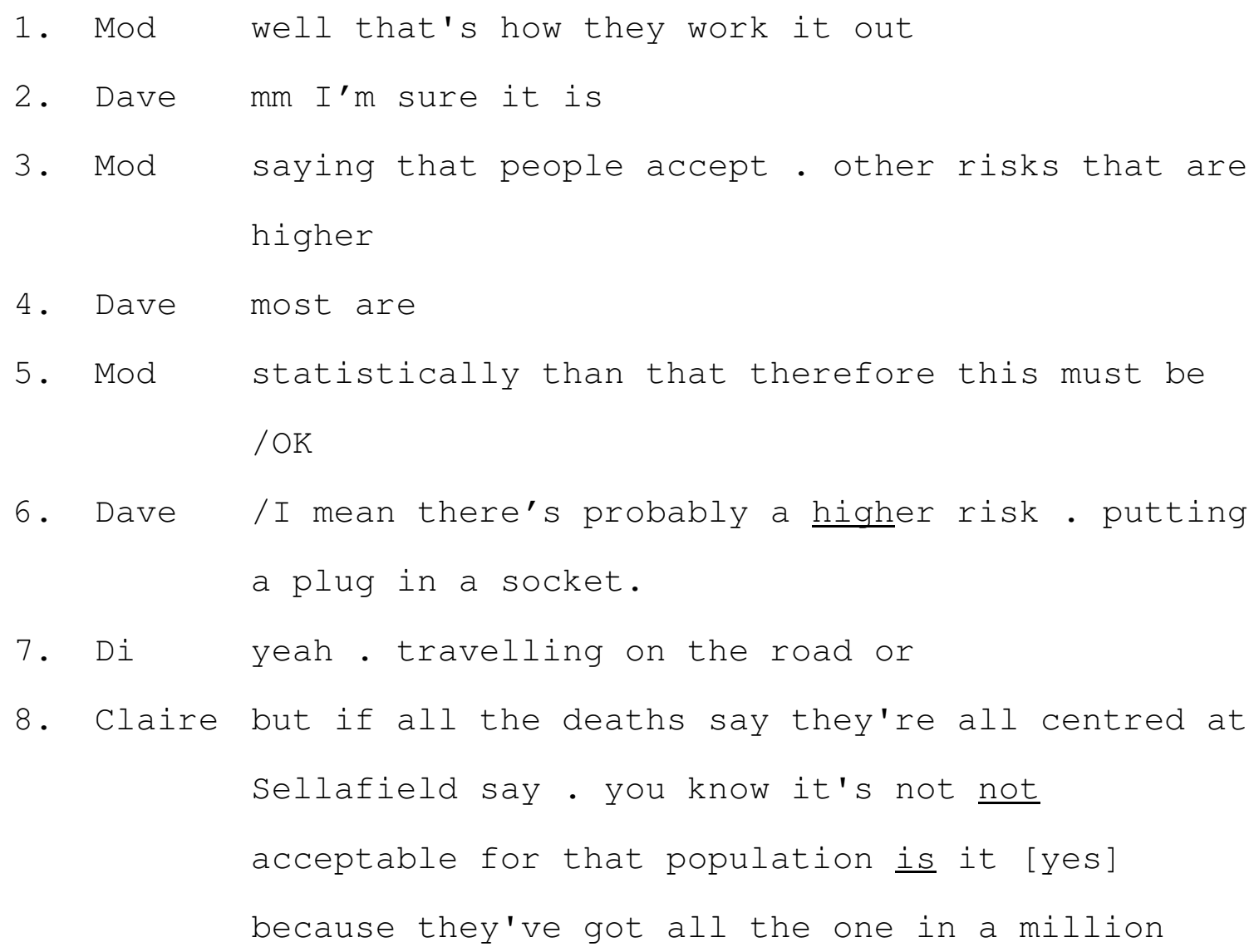




$$
\begin{aligned}
& \text { and I had to spend a lot of time looking at } \\
& \text { everything I gave him [yes] um and that was ten } \\
& \text { years ago [right] twelve years ago now [yes] um } \\
& \text { (1) and I don't like the idea- I don't know- I } \\
& \text { mean, supposing they go down this line [yes] is } \\
& \text { it going to be too late. um. by the time they } \\
& \text { realize that something's wrong [yes] is it too } \\
& \text { late [yes] do you see what I mean [yes] and it's } \\
& \text { too late [yes] I don't know } \\
& \text { y- when you eat it yourself is one thing but } \\
& \text { would you give it to your children is another } \\
& \text { isn't it [right] }
\end{aligned}
$$

Anna's statement (turn 2) is full of bids for the support of the other participants: 'I don't know ... I mean ... is it? ... do you see what I mean? ... I don't know'. And she is nudged along by the moderator's continuers ('yes . . yes'). Josie's statement (3), on the other hand, is neatly phrased as a general rule, with a generic you, again with a tag question ('isn't it') suggesting that this is an already shared sentiment. Peter's response in 4 starts 'there again', a way of acknowledging a previous turn as a prelude to disagreement (Myers, 1998). He does not to question either the time commonplace or the commonplace of self and others, but proposes another commonplace, that 
Commonplaces of past and future occur frequently in these focus groups. This may be partly because they are prompted by moderators' topic guide questions about change (especially in one of the research projects that provided my data). But commonplaces are also a way of acknowledging the limitations of the perspective from any one point in time, and there fore of presenting, politely, the potential limitations of one's own view. And they raise issues of responsibility across the years and across the generations without making a direct moral evaluation of other participants.

\section{Self and others: 'would you give it to your children'}

Commonplaces of self and others also divide into two, both concerned with the moral issues of apportioning responsibility:

- One must take responsibility for others as well as for oneself.

- The person who risks must be the person who benefits.

The responsibility for others is typically expressed as a responsibility for one's children, as in the previous example. In Example 6, Anna uses the time commonplace ('is it going to be too late'), and then Josie comes in at turn 3 with a clear statement that the issue is self and others. (The moderator's short supporting utterances are here included in brackets).

\section{Example 6 - Uncertain World: Green Consumers}

1. Mod Anna wh- what do you think. I mean do you think it's- they're doing it fo:r for-

2. Anna I don't like the idea of it [right. ye:s] I don't like the idea of people messing around. again it's-you see my son was allergic to food. 


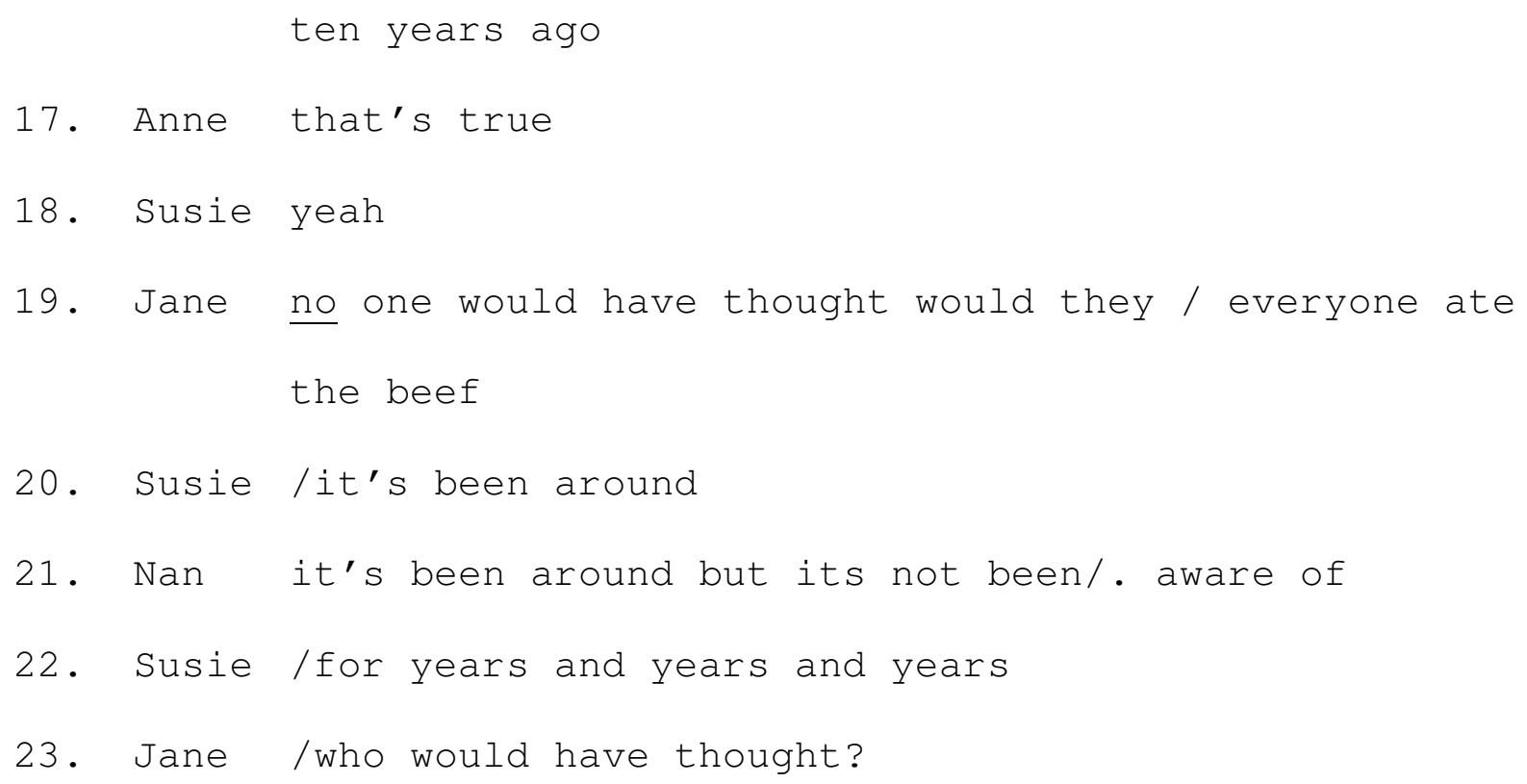

As Susie and Helen successively add to their scenario in 3-9, they treat it as a view of the future they all share. The threat is vague; it might emerge 'when you have children or I don't know' (9), but the vagueness, 'could do anything' is part of the argument. And when the Moderator calls it 'this twenty year thing' (13) with no further specification of what he is referring to, he suggests he too recognizes Helen's reference six turns earlier as a summarisable, familiar line of argument. Their response to him is to refer to BSE, a known failure in the past to foresee the future. The 'who would have thought?' (16), echoed in 19 and 23, implies without saying it directly that any new product could carry similar unknown dangers. The shared nature of this commonplace is clear from the way Jane answers her own question, and uses a tag question ("no one would have thought would they'), from the echo ('it's been around' / 'it's been around but it's not been . aware of') and from the extreme case formulation ('years and years and years'). Participants do commonplaces in collaboration. 


\section{Example 5 - Uncertain World - Working Women Lancashire}

1. Anne you don't have it touching your skin you can see the reaction can't you

2. Jane yeah that's right

3. Susie you wouldn't think about it until something actually hap/pened

4. Jane /yeah

5. Helen /and it would probably happen fairly immediately

6. Nan yes it would

7. Helen the tomato might come out in twenty years time as

8. Mod is that right

9. Helen it might be when you have children or I don't know [yeah yeah] could do anything but the washing powder would show up straight away

10. Jane yeah

11. Mod is that / did you

12. Jane by the way it ruins your clothes or gives you an irritation [yeah] or whatever isn't it

13. Mod do you think this twenty year thing is. you know a possibility with these tomatoes? (1)

14. Jane oh yeah!

15. Nan its a worry isn't it

16. Jane who'd have though about mad cow's disease [uh huh] 
commonplaces of proximity (one's first concern is with local problems) (Myers and Macnaghten, 1998). The commonplace that concern diminishes with distance has a long history (Ginzberg, 1994; Boltanski, 1999), and it does indeed arise frequently in these transcripts. But Burningham and Thrush (2004) found another ordering was possible, when their interviewees in Cefn, Wales would overlook a local source of pollution because the factory was part of the community's way of life, while still being concerned with distant sources of pollution. The commonplaces are invoked, not as general principles in a consistent system, but as familiar ways of responding to immediate conversational dilemmas while saving the face of other participants, by appealing to the shared experience of a mother's responsibilities, or to the shared the experience of living in a small, close community.

\section{Time: 'who would have thought?}

Time is crucial to discussions of risk: 'The center of risk consciousness lies not in the present, but in the future. In the risk society, the past loses its power to determine the present. Its place is taken by the future, thus, something non-existent, invented, fictive, as the cause of current experience and action' (Beck, 1992: 34). Much of the rhetorical work in these groups involves imagining the future, or projecting our current state back on the known past. In Example 5, the participants have been asked why they are less worried about GMOs in washing powder than about those used in tomato purees. Again, there is a face dilemma, a potential implication that one is either careless (using the powders) or impractical (finding dangers in every product). In turn 1, Anne is developing a contrast of outer and inner contact, what one can see and can't, but Susie parallels it in turn 3 with a different commonplace, what one sees now and what will see in the future. 


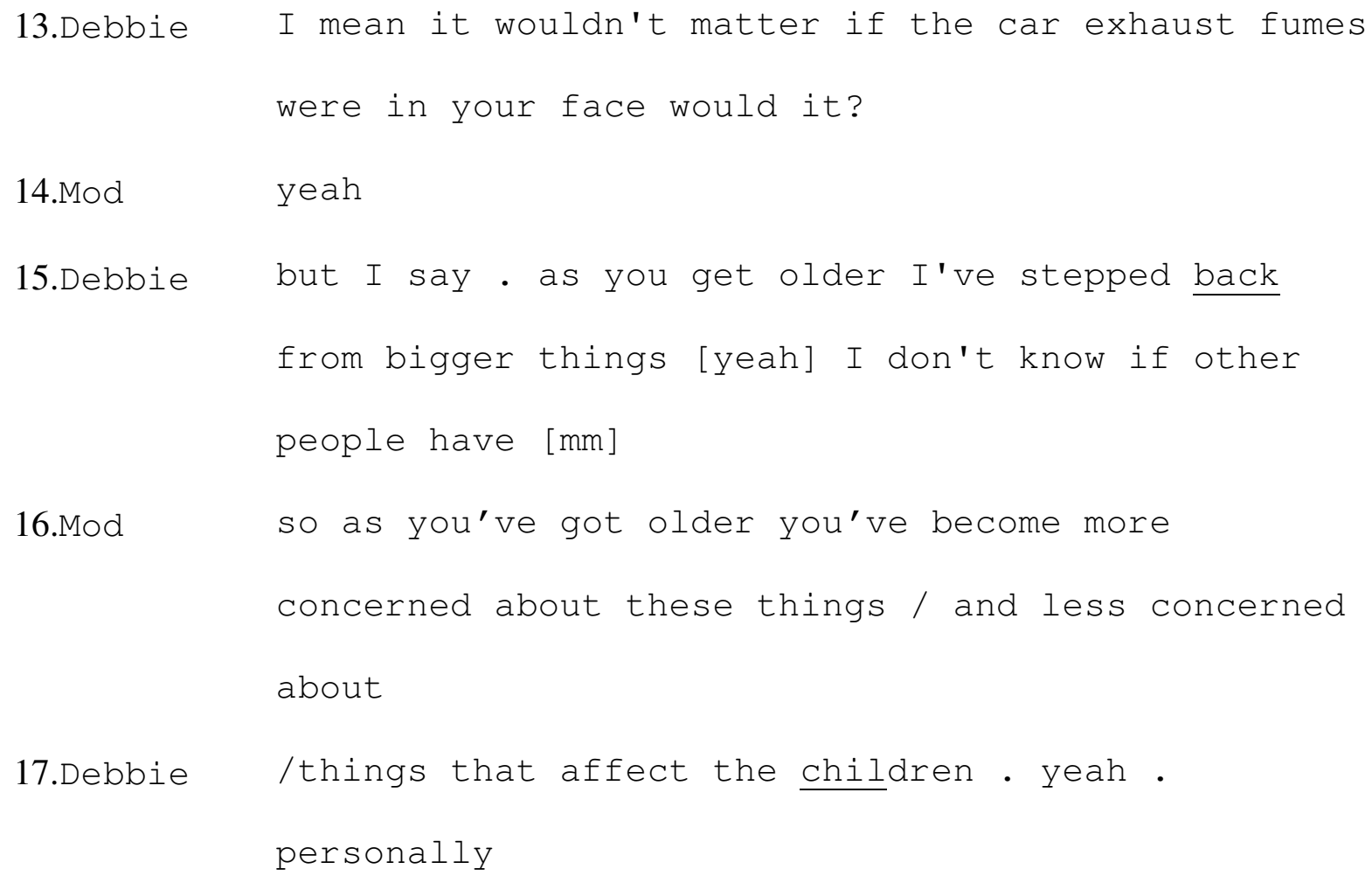

In turn 4, Debbie responds with a carefully phrased rebuttal of the implication that they are unaware of larger problems; she chooses extremes of large scale catastrophe vs. small-scale distaste. She hedges her assertion of priorities: 'a bit more important than perhaps,' as if some unnamed interlocutor might think turds in the sea were nearly as important as a nuclear power plant explosion. She goes on to present another, similar contrast, between the global damage to the ozone layer and the local problems of car fumes (9-13). She accepts the idea of a scale of concerns, but offers a different scale, as the moderator chimes in with continuers: 'what affects you personally' (6), 'things that affect the children' (17). And she asks others to confirm that the scale to which she is appealing is immediately recognisable: 'I don't know if other people have'.

Again the answer to one commonplace of proximity (problems that are bigger in scope matter more than problems that are more restricted in scope) is another 
participants' concerns; on the other hand, a list of local problems can be presented as an indication of lack of wider awareness or concern.

\section{Example 4 - Rhetorics of Sustainability: Thornton}

1. Mod

$$
\begin{aligned}
& \text { right. yeah there's certain patterns here so. } \\
& \text { there's the traffic fumes . there's the sewage. } \\
& \text { there's the ICI. the beaches . all these are } \\
& \text { quite sort of . they're local things / really } \\
& \text { aren't they really? }
\end{aligned}
$$

2. Debbie

$$
\text { / } \mathrm{mm} \text { yeah } \mathrm{mm}
$$

3. Mod

yeah?

4. Debbie

I mean if the nuclear power station went up it's a bit more important than perhaps if we've got turds in the sea isn't it. but I mean as they say as a mother [laugh?] you you tend to step back from it

5. Mod right

6. Debbie it's what affects you personally/

7. Mod /yeah:

8. F

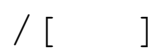

9. Debbie rather than is the ozone layer still there 10.F [laugh

11.Debbie and are we sizzling up because the sun's coming through

12.Mod right 
Sean's argument is complex. First he draws on his own and his family's experiential authority as farmers. Then he offers an argument as he says it would be offered by farmers. He takes on the ways of speaking of a risk manager, comparing forms of risk, as if he had figures on BSE or MMR related deaths. Then, after 'so', he makes the intended conclusion explicit in a rhetorical question: if the MMR vaccine is allowed, then sales of beef should be allowed. No one challenges the figures, here or elsewhere. Instead Sally, while disagreeing, echoes Sean exactly - 'more babies die of that ...' / 'more babies are going to be born you know .... She shifts to a different comparison (from MMR/BSE deaths to MMR/rubella deaths), while keeping the same commonplace of greater and lesser risk.

A risk communicator whose job it is to present accurate statistics of risk may find it maddening that these participants are reluctant to challenge such fanciful figures. But this reluctance makes sense in terms of the rhetoric of everyday talk; one cannot in ordinary conversation challenge the figures without threats to face, but one can still disagree by challenging the terms of the comparison, and asking in what terms it is greater or lesser.

\section{Proximity: 'they're local things'}

One dimension of contrast that seems to be accepted across a range of groups is that between the near and the distant. This is not just a matter of selfish fear from what might affect one's own back yard; it also raises issues of individual agency in relation to the hazard proposed. For instance, in Example 4, Debbie responds to the Moderator's characterization of the environmental concerns they have listed as 'local things'. The face dilemma is that on the one hand, a list of local problems shows the authenticity of 
1. Alan it's not the trust them as well because look at the BSE thing it's like

2. Sean yeah but the BSE thing was blown up out of all proportion

3. Alan yeah, it is/but

4. Sean /I mean . that was one of the things. I mean. I was telling you before I used to be a farmer. I grew up on a farm my family's got a farm and it was dairy and beef . and sheep . and . the biggest thing that upset a lot of the farmers on that was the fact . the very simple fact. that. if you inject-you know the Rubella the multi jab that babies get . more babies die of that every year than . will ever die of BSE. you know [ ] going into the if there was a link with the uh CJD in humans. so OK so they've banned they did a blanket ban on beef so why don't they ban the / Rubella thing

5. Sally /but more babies are going to be born [mm] you know - with disabilities if they don't have the Rubella jab

6. Mike exactly exactly

7. Sally far more than will die from Rubella 
effects, so can another drug. But this commonplace is a contradictory pair, not a general principle; on the same grounds one can insist that an event that hasn't happened should be treated as real because it could happen, or that it should be treated as unreal because it has not yet happened, or does not always happen.

\section{Scale: 'more babies die of that'}

One of the standard forms of institutional rhetoric about risk is the argument that people will undergo one risk (traveling by car, having an X-ray, flying, living in an area where rocks emit radon gas) while refusing to undergo what is said to be a smaller risk (living near a nuclear power plant, consuming artificial sweeteners) (one of many critiques is in Hansson, 2004). Of course size is not just a matter of number of number of people affected, or of probability: proximity, uncontrollability, and irreversibility may also lead to a risk being perceived as 'bigger'. Official agencies making these comparisons may try to associate them try to associate them with exact figures, for instance, increased deaths per million in the population (Gigerenzer, 2002). But the focus group participants in our data show little concern with exact figures or correct mathematical calculation. They are more likely to use extreme case formulations (Pomerantz, 1986; McCarthy and Carter, 2004): 'millions', 'dozens', 'again and again', or 'ever'. Pomerantz argues that extreme case formulations show an orientation to controversy, an expectation of possible contradiction. In Example 3, the face dilemma is the implication from the moderator in a previous turn that the participants trust the scientists. Alan offers 'the BSE thing' as a case the implications of which are known to all the participants, and Sean challenges him.

\section{Example 3 - Global Citizenship: Creative Professionals 2}


10. Danielle yeah

11. Gerry it just depends on how big the risk is

In turn 1, the Moderator stresses 'absolutely', minimizing the risk. Two participants break in at this point, and he chooses one to speak. In 2, 5, and 7, Danielle repeats 'still a risk', a way of referring to the possibility even when something is unlikely. She does this collaboratively, by using tag questions (a short question at the end of a statement), 'isn't it' (2) and 'isn't there' (5). And it is not she who invokes this commonplace; 'that's what they're saying' - it is ironically attributed to 'they', to the very institutions reassuring her. In turn 9, Gerry comes back with the opposing commonplace, echoing Danielle exactly, down to the same tag question, 'isn't there' (on repetition, see Tannen, 1989; Carter, 2004). The 'isn't there' implies that listeners will recognize 'there's a risk with everything' as a commonplace. And Danielle does acknowledge it, even though she has just said something that might be taken as having an opposite tendency, to maximize rather than minimize risks. Instead of directly contradicting Danielle, Geoff echoes and shifts the argument to a commonplace of scale, 'it just depends how big the risk is' (see the next section).

As Geoff shows in this example, the other side of saying that anything might be a risk is to say that everything could be treated as risky. Tulloch and Lupton give an example, an interviewee who says 'there is just a level of risk in walking around' (2003: 18), and there are variations of this kind of example in my data. Aristotle has many possible variations on the topos of the possible and impossible, for instance 'if of two similar things one is possible, so is the other' (Aristotle, 1954: 1392). So if one nuclear plant can have an accident, so can another; if thalidomide can have unforeseen side 
This set of commonplaces seems to cut off any discussion, since they undermine any calculation of possibilities. It may be more useful to see them as addressing face needs, instead of seeing them as attempts to settle an issue.

In Example 2, the Moderator is reading out a description from the nuclear industry of various categories of nuclear waste. The face dilemma posed here is between accepting the reassurances of an authority, on the one hand, and seeming to open up an endless line of potential worries, on the other; the Moderator's quotation challenges either the autonomy of the participants (their ability to make up their own minds) or their security.

\section{Example 2 - Front End Study: Bridgend}

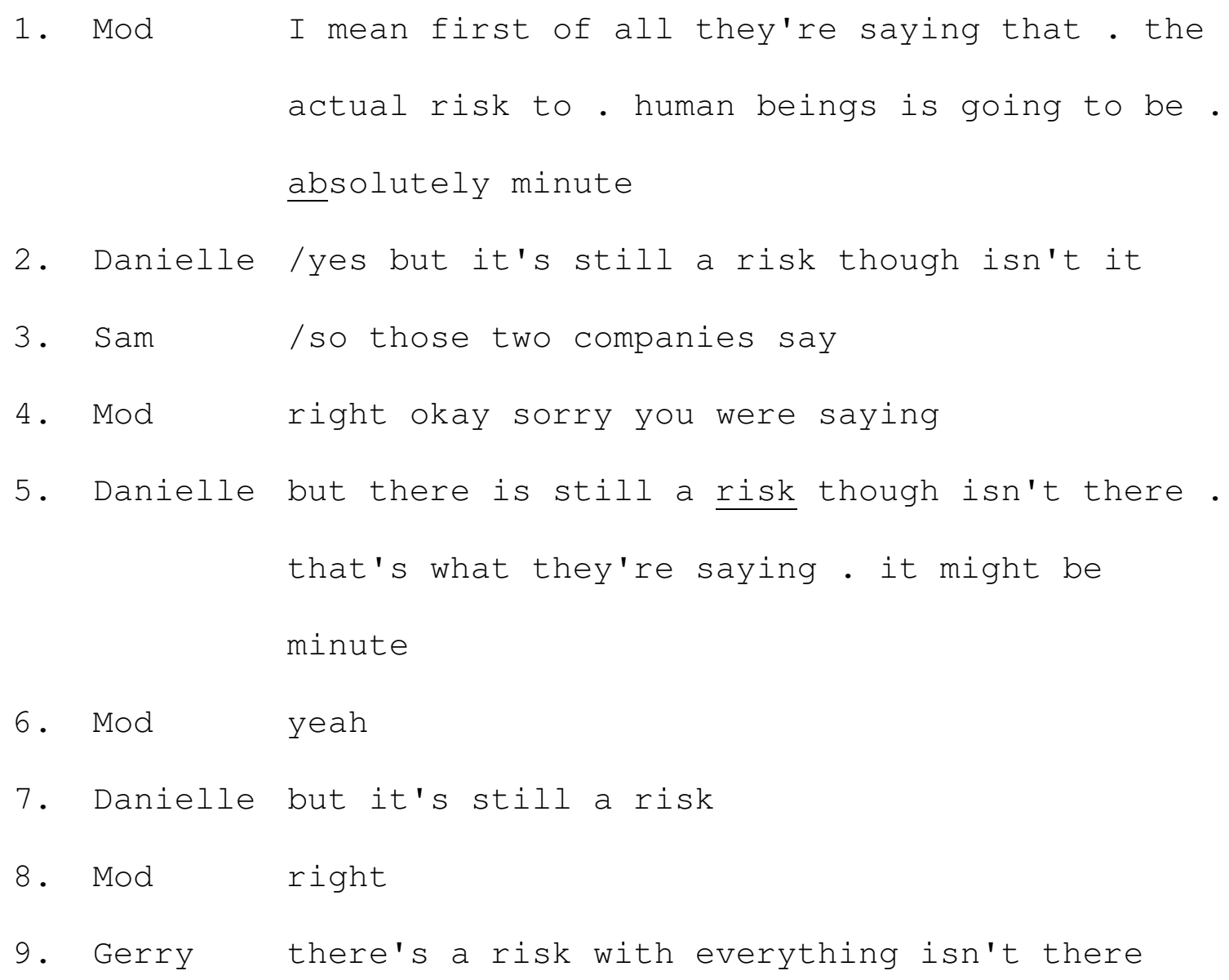


it does just here (agree, disagree, mitigate a disagreement, close a topic), instead of trying to find out the participant's intentions.

Some readers may also be puzzled by the qualitative nature of this analysis. The common-ness of a commonplace is not a function of its statistical frequency in the corpus, but of its recognition by participants in following turns as being the sort of thing people say. I have not tried to quantify the references to risk issues, the rhetorical strategies used, or the categories of commonplaces. As will become apparent, one extract may involve several kinds of devices, each of them taken in different ways by the participants. Aggregating them across different extracts and transcripts would only be misleading. My presentation involves organising the commonplaces into five loose families. Again, the point is not to quantify them, to show that possibility commonplaces come up more or less often than proximity commonplaces, but to see how participants present such commonplaces and respond to them in each case. To summarise, I am interested in how participants do these actions, not why or how often.

The five families of commonplaces I will present are based on issues of possibility, scale, proximity, time, and self and others. I will argue in my conclusion that they correspond to five different issues in the wider discourse of risk.

\section{Possibility: 'There's a risk with everything'}

Contingency is a central aspect of risk. It arises rhetorically in different and contradictory forms:

- If something is possible, then there is a risk that it can happen

- Not everything that is possible will happen

- It is impossible to deal with all possible risks 
Moon, 1998; Wray, 2002). They are recognised, not by specific words, but by the way the argument presented is taken in the next turn by other participants. So, in Example 1, the comparison to winning the lottery is taken as standing for an extremely small chance, it is recognisable as a commonplace of scale, and the next turn shows it is taken by other participants as a commonplace.

Two methodological assumptions in my approach, which is based on conversation analysis (CA), may need emphasis for those more familiar with other approaches to discourse analysis. Rhetorical terms suggest strategic language use and intentional choices. But conversation analysis does not make claims about participants' intentions (Heritage, 1984; Hutchby and Wooffitt, 1998; Silverman, 1998; ten Have, 1999). Instead, CA argues that participants make available to others the orientation they are taking to the conversation at hand, so that they can together manage the turn by turn progress of the talk. The analyst looks at just what they make available to each other. To take a classic example, before the closing of a telephone conversation, participants typically go through a pre-closing routine involving six precisely timed turns, in which they signal and check that both sides are willing to have the conversation close, and that neither will now open up a new topic (Schegloff and Sacks, 1973). This observation does not constitute a claim that participants consciously prepare the turns or time them for this effect; they just do it, and if it isn't done just this way, they may treat it as odd, and try to come up with an explanation of the oddity ('He just sort of hung up on me'). When a participant uses a commonplace such as 'there's a risk with everything', the analyst looks for the meaning of that utterance in its placement in relation to the previous turn, for what 
did not know each other, led through a topic guide by a moderator. The projects dealt with such topics as sustainability, citizenship, animal experimentation, genetically modified organisms, and nuclear waste. In some of them the moderator raised risk issues explicitly, while in others such issues came up in the course of discussion of changes in the neighbourhood, or attitudes to animals, or responses to TV commercials and documentaries. I grant that the genre-specific nature of interaction in focus groups constrains the kinds of talk that could occur (Bloor et al., 2001; Macnaghten and Myers, 2003; Puchta and Potter, 2003; Myers, 2004), and one would find different kinds of interaction in one-to-one research interviews, doctor-patient interaction, dinner table discussions, web discussions, or broadcast debates. But I would argue that focus groups, for all their constraints, provide a controlled context that can raise issues about interaction that can then be explored in other genres and settings.

I extracted passages in which the participants talked about public choices involving uncertain hazards to health or life, including the moderator's prompts as well as participants' turns. For each extract, I coded rhetorical devices such as jokes, narratives, use of numbers, and references to expert knowledge. This paper illustrates some of the devices coded as commonplaces. In the data I am studying, commonplaces are introduced in response to dilemmas, contradictions of which participants are themselves aware, and of which they expect other participants to be aware too (Shotter, 1993). They implicitly acknowledge that this issue is an issue with sides, and that there are opposing sides (Billig, 1987).

Commonplaces use formulaic language. But they are not fixed expressions like idioms or proverbs; we cannot search for them using specific strings (McCarthy, 1998; 
using different strategies of identification, and drawing different circumferences around the issue.

It might be asked whether the participants in the focus groups I analyse, talking about uncertainties in their lives, are talking about risk. Tom Horlick-Jones (2005) distinguishes between 'contingency', which is the 'uncertainty about outcomes of actions and decisions' found in any way of life, and 'risk' as 'a discourse and a set of practices, a gaze one might say ... which is concerned with the economically efficient and accountable management of contingency' (257). Participants in any focus group talk about contingency: one might lose one's job, crash one's car, win the lottery, get sick. But they also use the 'technical discourse of risk', the language of risk assessment, comparison, costs and benefits. Instead of contrasting expert and lay views of risk, Horlick-Jones sees both as using similar strategies interactions with others. One of the features he identifies in these interactions is the way 'The arguments draw upon shared interpretative resources, or "lay logics" [(Yearley, 1987)], like "fear could be dangerous", "right to know", and "the danger is in your hands". These logics seem to reflect broad patterns of shared experience among the speech community in question' (262). These lay logics are similar to what I am analyzing, but by calling them commonplaces, I am focusing on the way they are used rhetorically and reflexively as 'what everyone knows', with collaborative construction and checking of responses. Because they are taken to be shared, they can be offered to mitigate threats to face.

\section{Data and methods}

I draw on thirty focus group discussions drawn from six research projects (see Appendix 1 for list and references). The discussions typically involved participants who 
to social practices (Wynne, 1995; Irwin and Wynne, 1996; Wynne, 2001), complex and contradictory responses to risk are embedded in the everyday lives of sheep farmers, parents, people with medical conditions, or workers in nuclear plants. In a similar approach, Joy Parr talks about the 'vernacular understandings' of what makes good water. The commonplaces I study show the kinds of tensions that Wynne sees in, for instance, the response of Cumbrian sheep farmers to policy decisions after Chernobyl polluted their pastures, and Parr sees in responses to an E. coli outbreak. The difference between my approach and that of Wynne or Parr is that they look for underlying understanding, while I focus on rhetorical moves responding to the immediate interaction.

Some risk researchers have seen the tensions in risk talk in terms of rhetoric. Jennifer Hamilton (Hamilton, 2003), analyzes public discussions about a dilemma posed in the cleanup of a radioactive waste site, describing the disjunction between different views in terms of Kenneth Burke's (1984) frames of acceptance. She applies this way of looking at arguments to Plough and Krimsky's (1987) distinction between technical rationality and cultural rationality, so that her work:

extends Plough and Krimsky's by envisioning these risk orientations as broad meaning systems that serve as sources for rhetorical invention for participants as they interpret risk experiences, formulate persuasive appeals, and promote mutual understanding by strategically combining aspects of these rationalities (293).

The two kinds of rationality are then seen as rhetorical resources, allowing participants to identify useful details, get their points across, and mediate differences. Following Burke, she sees the two sides in the debate she studied as defining the situation in different ways, 
research; that is, such issues as certainty, dread, and controllability come up again and again in people's discussions, whatever the group and whatever the risk. But Slovic's work is psychometric, and assumes these factors are in the minds of individuals, to be elicited by questionnaires. In my focus group data, participants talk as if their listeners were already aware of such factors as voluntary vs. involuntary risk (see Example 1); that is, these factors can be seen as rhetorical tools available to all participants. This rhetorical use suggests that when people mark a preference on a questionnaire, they are not just expressing their underlying and personal view, they are recognizing the sort of thing people like them normally say on issues like this.

The commonplaces that I study certainly reflect the culture in which the focus groups were conducted; for instance, the invocation of 'you have a choice' as a satisfactory solution to the risk of BSE/CJD works in our culture and may not work in others. Mary Douglas and Aaron Wildavsky situate risk in a culturally shared set of understandings, practices, and social relations: 'The different social principles that guide behavior affect the judgment of what dangers should be most feared, what risks are worth taking, and who should be allowed to take them' (Douglas and Wildavsky, 1982: 6). But Douglas and her colleagues do not study what people in the cultures under study actually say; looking at cultures from their broad level of generalization, and looking for the structures that make a culture work, they may lead us to underestimate the rhetorical artfulness of individual performances.

Ethnographic research in science and technology studies has done more to stress the asymmetrical relationships involved in everyday responses to risks, especially to environmental hazards. For Brian Wynne and other researchers studying risk in relation 
around 'scares', see Tulloch and Lupton, 2003; Cook, 2004; Richardson, 2005). He hesitates in 4 and 7 ('well', 'you know', 'what is it') in a way that that suggests that something is delicate about what follows. He responds to the dilemma posed by the moderator with a commonplace comparing two chances, that of an event people hope for (winning the lottery) and that of an event they fear (getting CJD from BSE-infected beef). He gives a vague attribution of this comparison 'what did somebody say'.

A risk analyst could at this point raise questions about the nature of this comparison (A dozen times? Are the chances of developing CJD known at all? Are they comparable outcomes?) But the other participants don't raise these questions. Instead the next turn is another implicit comparison, the risk of smoking and the risk associated with eating beef, introduced with 'I mean', which is typically used to signal that what follows is a restatement in other words (Schiffrin, 1987). Smoking could be seen as a different kind of issue from BSE, but Andrew comes in at the word 'choice' with a 'yeah' (turn 9) that acknowledges Jeff as saying, for his purposes, the same sort of thing. The response to a commonplace is typically another commonplace. All this care suggests that the speaker is not just conveying information to other participants; he must take into account ways they might respond to him and to this topic.

\section{Commonplaces and risk studies}

An analysis of commonplaces both complements and extends some existing lines of social research on risk, dealing with issues of risk perception, cultural systems, everyday practices, and expert and lay views.

The well-known factors in risk perception proposed by Paul Slovic and his colleagues (Slovic, 1987; Slovic, 2001) turn out to be fairly robust in focus group 
Risk Commonplaces - 6

suggestible, while if they aren't influenced, they may seem uninformed (see transcription conventions in Appendix 2).

Example 1 - Global Citizenship: Small Business Owners

1. Mod but do people do you feel like you personally were influenced say in the BSE case

2. Andrew yeah

3. Mod or in global warming or indeed that you're influenced by - what the media tells you

4. Andrew well to me to me the BSE scare was just another one in a long run of you know. what with eggs and wi- with all sorts of / scares

5. Jeff yeah eggs chickens

6. M ( ) that's what I've seen that's

7. Andrew in the end well I listened to what had to be said and read it in the papers as well and then decided that. you know . what is it >what did somebody say< there's more chance of winning the lottery a dozen times in your life haven't you [mm] something than getting BSE

8. Jeff I mean when you think about it like smoking you have the choice/

9. Andrew /yeah

Andrew calls it 'the BSE scare', placing the events in a category he assumes is familiar to other participants, and suggesting that the anxiety was perhaps unnecessary (on discourse 
ability to make such decisions for myself, whatever you might say. Risk talk is not just about risk, it is about me and you and them, and any statement may have more to do with the immediate context of interaction than with underlying attitudes or with calculations of probabilities and dangers.

One way (or a set of ways) of mitigating possible face threats is the use of commonplaces, what the rhetorician Richard Lanham has defined as 'a general argument, observation, or description a speaker could memorize for use on any number of possible occasions' (Lanham, 1968: 110). Examples would include the comparison of the greater (MMR risk) and the lesser (CJD risk) used in the opening example, or the linking of past events to present events, or the statement that everything is a risk, or the invocation of responsibility to children (Myers and Macnaghten, 1998). There have been studies of what rhetoricians call 'topics' since Aristotle's Rhetoric (ca. 350 BC), and lists of ways of approaching an argument remain part of textbooks on writing and public speaking today (for discussion, see Kinneavy, 1971). While commonplaces are used in any form of persuasion, from formal judicial proceedings and campaign debates to pub arguments, and on any topic, I argue that they are especially useful in keeping risk talk going, because they can incorporate contradictions, refer to shared culture, invoke shared experience, and orient to relationships among participants.

We can see how common experience is invoked in the conversational context of the statement I have already quoted. The example begins with the focus group Moderator posing a dilemma by asking whether the participants feel they are influenced by the media. It is a dilemma because if they are influenced, they can be seen as passive and 
back to Aristotle; it differs from the sense the term usually has in risk research, where it is usually contrasted with 'reality' or 'practice'). I argue here that some of these rhetorical strategies recur because risk talk is problematic. I will restrict myself to one kind of risk, issues involving public choices around uncertain dangers to life or health, because those are the kinds of issues that occur in my focus group data. Even with this restriction, and even in groups not explicitly concerned with risk, there is a range of risk topics, from BSE (as we've just seen) to the Measles Mumps Rubella (MMR) vaccine, global warming, nuclear waste, traffic, food contamination, and sewage in the sea.

These discussions raise the sorts of issues familiar from the literature on risk studies: factors of risk perception(Slovic, 2001), expert information and trust (Wynne, 2001; Frewer et al., 2003), local identities and stigma (Gregory and Satterfield, 2002; Burningham and Thrush, 2004), reflexivity in conceptualizing the self and society in relation to the distribution of dangers (see for example Lupton, 1999; Tulloch and Lupton, 2003). But most of these studies treat what people say in terms of its summarisable content, where I am interested in its form and function, in the ways people do things with these statements.

I argue that risk talk involves 'face work', which is what Erving Goffman (1955) calls the practices of people in conversation as each maintains the others' sense that they are seen as esteemed and autonomous. For instance, if we are at a restaurant ordering, and I say I don't worry about the threat of CJD, I am implying that you are aware of a possible threat of beef from BSE-infected cattle, and I know something, and trust that knowledge, and act on it, and imply that other views, perhaps your view, may be gullible or alarmist or impractical or ill-informed, and imply further that I have the right and the 


\section{Introduction}

This paper is about what people are doing when they say something like:

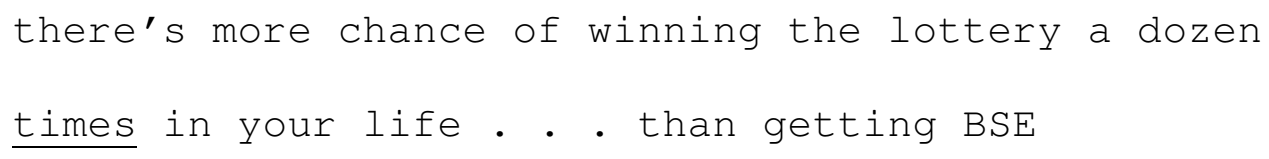

I am not interested in the particular calculation proposed here, but in how lay people use this sort of statement in interaction. The dilemma is whether to eat beef or not, after learning about the risk that Bovine Spongiform Encephalopathy (BSE) in cattle could lead to Creutzfeldt-Jakob Disease (CJD) in humans. A participant offers this statement to a group as an extreme form of comparison, as a familiar, recognisable form of argument, and as a contribution that responds to the dilemma, and settles it for present purposes. In particular, I am interested in the ways people use commonplaces, these apparently general and generally accepted arguments in talking about risk, and in the particular forms these repeated arguments take in conversation, what they follow and what follows them. I will trace the use of commonplaces in focus group transcripts from a number of different studies, on a range of different topics.

Anyone who has analysed qualitative data on risk issues will recognize that some patterns of talk turn up repeatedly (Hinchliffe, 1996; Michael, 1996; Wynne, 1996; Macnaghten and Urry, 1998; Waterton and Wynne, 1999; Lupton and Tulloch, 2002; Frewer et al., 2003; Richardson, 2003; Burningham and Thrush, 2004; Cook, 2004; Horlick-Jones, 2005; Parr, 2005). That is why one quotation can often stand for a number of similar utterances. One way of accounting for these repeated patterns is to see them as rhetorical strategies, that is, familiar forms of persuasion that take into account an audience and its interests. (This definition of rhetoric as 'modes of persuasion' goes 


\section{Abstract}

Talk about risk is problematic for interaction; it can involve the speaker or hearer saying things that threaten participants' 'face', the ways they want themselves to be seen by others. One way of dealing with these threats to face, and to keep the conversation going, is the use of commonplaces. Commonplaces, generally applicable and generally known arguments, play an important role in interaction, invoking shared, taken-for-granted perspectives embedded in familiar roles and everyday practices. They are similar to some of the frames discussed in risk communication, but they focus our attention on rhetoric and interaction rather than cognition. In this paper, I show how commonplaces are used in focus group discussions of public choices involving dangers to life or health. They tend to be used in response to dilemmas, when a speaker is put on the spot, and they tend to lead to other commonplaces. Analysis of commonplaces supports those who argue that studies of public perception of risks and programmes of communication about risks need to be sensitive to the personal interactions, rhetorical strategies, and cultural embeddedness of any risk talk. 


\title{
Commonplaces in Risk Talk: Face Threats and Forms of Interaction
}

\author{
Greg Myers \\ Linguistics and Modern English Language \\ Lancaster University \\ Lancaster LA1 4YT \\ g.myers@lancs.ac.uk
}

home phone: 01524388601 